\title{
Research on Tilt-up Building System and the Key Technology
}

\author{
Jiankang Liu, Jinling Gao, and Tian Peng
}

\begin{abstract}
Derived from Tilt-up construction in North America, Tilt-up Building System conducts shear transfer through roof bracing and connecting support instead of roof skin, which makes design methods more complied with the national code. In this paper, the force transfer system of Tilt-up Building System is firstly introduced. Then a simulation with Sap2000 is performed and both of the deformation property of Tilt-up Building and stress characteristic of wallboard are obtained. Subsequently, design of Tilt-up wall is studied and a new wallboard form, Tilt-up wallboard with fixed constraints at the bottom and hinged constraints at the top, and corresponding design methods are proposed. Meanwhile, a simplified method of wallboard hoisting analysis is demonstrated. Finally, conversions of wind load and earthquake effect between Chinese code and American code are executed and a visualization procedure based on VB platform is developed.
\end{abstract}

Index Terms-Tilt-up building system, tilt-up wall, wind load, seismic effect.

\section{INTRODUCTION}

Portal frame is widely applied to plants and warehouse buildings, of which purlins and wall beams are often made of cold-formed steel, roof and wall maintenance structure being often composed of profiled steel sheet or light steel sandwich panel. On the one hand, the color plate exterior wall needs regular maintenance with generally a replacement cycle of every twenty years. On the other side, the requirements of the color plate wall are so rigid that the details of wall closing are relatively lax.

The application of Tilt-up Building System[1]-[7] in North America is applied in extremely extensively in the design of the non-living low-layer buildings, such as logistics center, business center, low storey office building. The roof of Tilt-up Construction must have enough in-plane stiffness to deliver the shear force caused by the wind load and seismic effect, where the skin effect is formed by utilizing the thick Deck plate and purlins. As shown in Fig. 1, the shear forces in Tilt-up Construction are delivered through roof bracing and connection bracing instead of roof skin, which makes design methods more complied with the national code.

Manuscript received August 30, 2016; revised October 23, 2016. This work was supported in part by the Shanghai Open Steel Structure Co., Ltd.

Jiankang Liu is the Shanghai Open Steel Structure Co., Ltd., Shanghai, China (e-mail: Jiankang_Liu@ yeah.net).

Jinling Gao was with Shanghai University, Shanghai, 200444 China. He is now an associate structural engineer with Jiankang Liu in Shanghai Open Steel Structure Co., Ltd., Shanghai, 200127 China (e-mail: Jinling_Gao@yeah.net).

Tian Peng is with College of Civil Engineering, Tongji University, 200092 China (e-mail: pt0796@163.com).

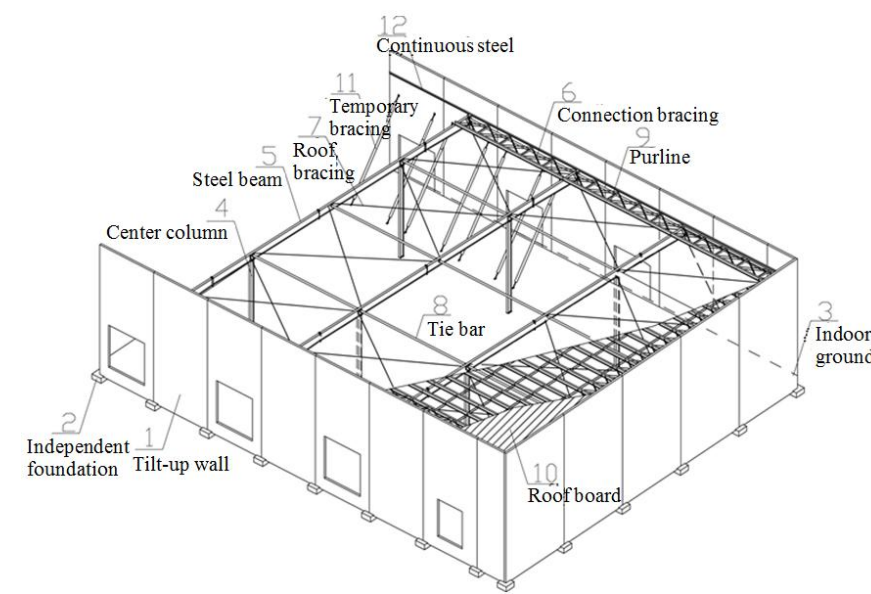

Fig. 1. Tilt-up building system.

\section{TILT-UP BUILDING SYSTEM}

\section{A. Force Transfer System of Tilt-up Building System}

The vertical loads exerted on Tilt-up Building System are delivered through purlines or steel beams to tilt-up wall, which makes tilt-up wall subjected to the eccentric axial load.

The wind load or seismic effect is transferred to tilt-up wall through roof bracing and connection bracing and the in-plane shear forces of Tilt-up wall are formed. Taking the wind load along the direction of gable wall as an example, the total shear forces of the both sides of the wall are formed through roof bracing and connection bracing. The shear force of each wall can be assigned according to the stiffness of the wall, which can be simplified as the assignment by the length of each wall when conducting calculation approximately.

$$
\mathbf{1} / K_{\text {total }}=\mathbf{1} / K_{\text {bending }}+\mathbf{1} / K_{\text {shear }}
$$

where $K_{\text {bending }}=12 E_{c} I / h^{3}, K_{\text {shear }}=G A / 1.2 h$

In order to ensure the effective transmission of lateral load of the flank and take economy into consideration, tilt-up wall can be set in the intermediate firewall. Tilt-up wall of firewall can be set with both the bottom and the top hinged and playing a role in the distribution of shear force; or be set as a cantilever plate with the bottom fixed without participating the distribution of shear force.

The following is a practical Tilt-up Construction Model. It is a four-span and double-slope logistics center with each span of $24 \mathrm{~m}$ ). The total length is $240 \mathrm{~m}$ and the column space is $12 \mathrm{~m}$. The structure is subjected to various loads including the dead load of $0.35 \mathrm{kN} / \mathrm{m}^{2}$, the live load of $0.3 \mathrm{kN} / \mathrm{m}^{2}$, the snow load of $0.7 \mathrm{kN} / \mathrm{m}^{2}$ and the wind load of $0.35 \mathrm{kN} / \mathrm{m}^{2}$ (Roughness: B type). The structure is located at the non-seismic zone. The overall model established in SAP2000 
software is shown in Fig. 2.

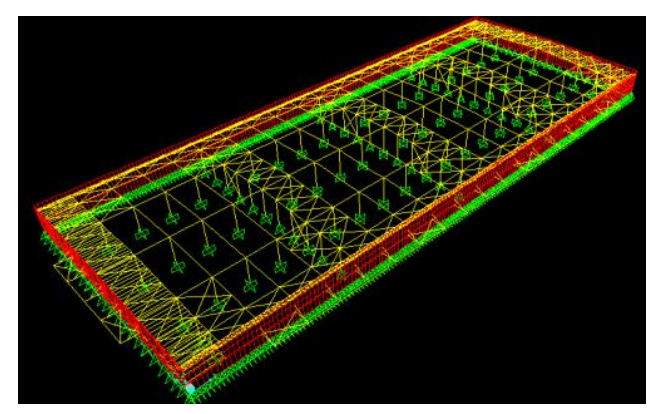

Fig. 2. Overall model established in SAP 2000.

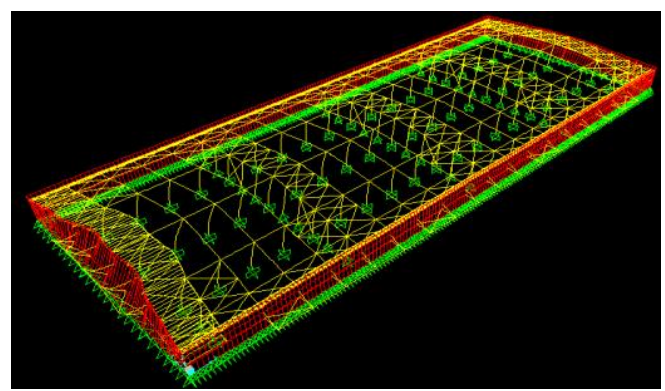

Fig. 3. Deformation of structure under the wind load along the gable.

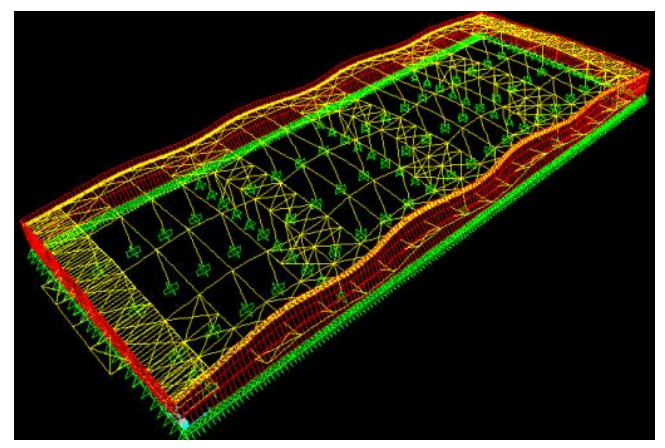

Fig. 4. Deformation of structure under the wind load along the flank.

As shown in Fig. 3, the deformation of building under wind load in the direction of gable wall distributes in the shape of a parabola along the span, and the maximum deformation occurs in the mid-span. The deformation gradually decreases along the length direction. As shown in Fig. 4, when increasing the stiffness of the rigid frame at the firewall and setting the roof bracing on both sides, the deformation of building distributes in a wavy shape along the length. The maximum deformation occurs in middle of the two firewalls or the middle of firewall and gable wall.

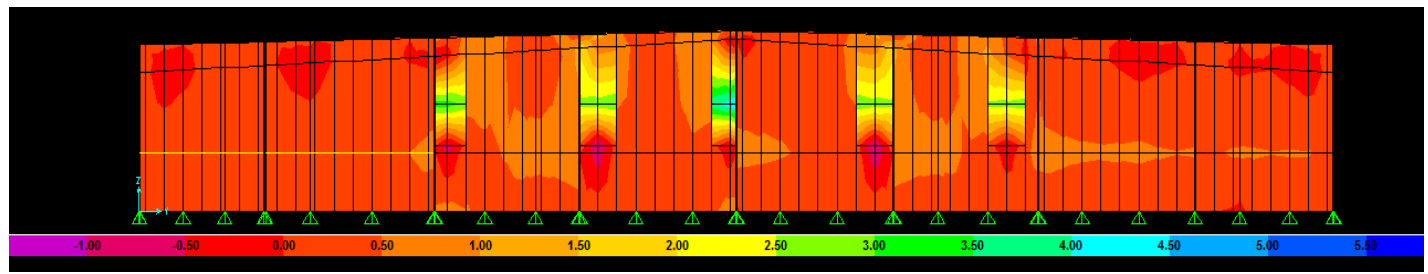

Fig. 5. Stress nephogram of gable wallboard under wind load along the gable.

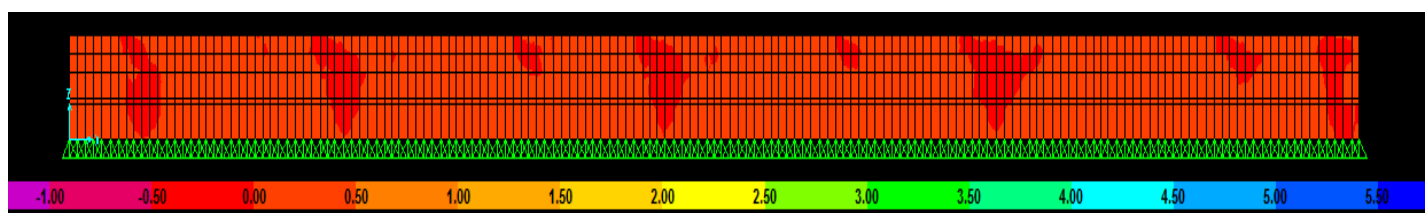

Fig. 6. Stress nephogram of flank wallboard under wind load along the gable.

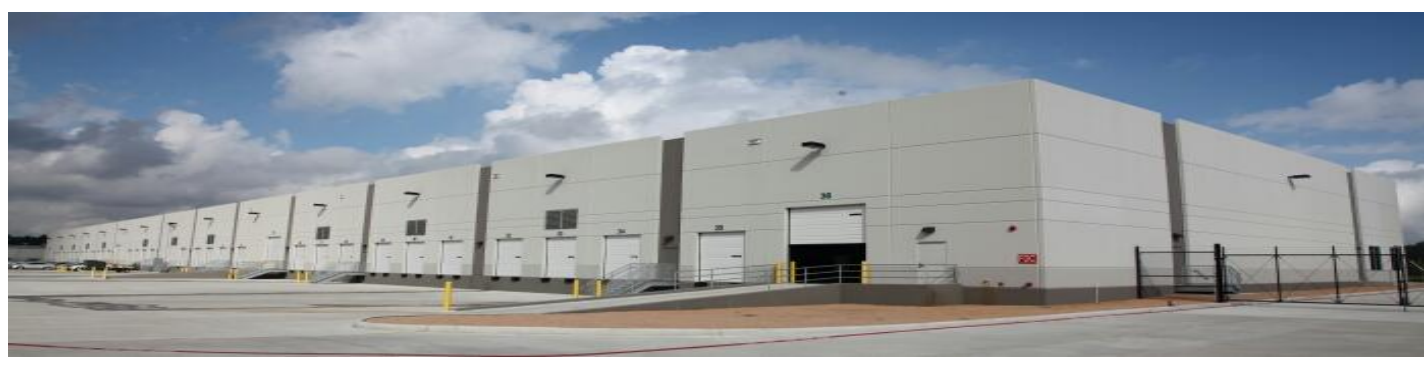

Fig. 7. Sketch of tilt-up building system.

As shown in Fig. 5 and Fig. 6, subjected to the wind load, the gable wallboard mainly suffers the out-of-plane bending moment and deformation, and the wallboard of the flank suffers in-plane shear force. The maximum stress occurs in the connection of the steel beam and the wallboard or the connection of the canopy and the wallboard.

\section{B. Advantages of Tilt-up Building System}

As shown in Fig. 7, the walls of Tilt-up Construction are composed of the reinforced concrete, with high strength, collision resistance, and less regular maintenance. At the same time, tilt-up walls are prefabricated on the spot. By using the flexible plate mold of the baseboard, different lines and chamfers can be created. Simultaneously, combined with a variety of surface treatment, the aesthetic effect can be gained. From the entire life cycle of the project, tilt-up building system is more economical than the portal frame.

\section{The Design OF TILT-UP WALL}

The mechanical model of Tilt-up wallboard should be established considering the wall holed and the form of the 
foundation. The slenderness ratio of the wallboard is stipulated in CSA [8] as below.

$$
l_{c} / h \leq \begin{cases}\mathbf{5 0} & \text { singlelayer reinforcement } \\ \mathbf{6 0} & \text { doublelayer reinforcement }\end{cases}
$$

\section{A. Designing Detail of Tilt-up Wall}

The bending moment of the wallboard is mainly caused by the lateral (out-of-plane) load (wind load or seismic action), which is much more than the moment caused by the eccentric effect of the axial load. Considering the eccentric effect of the axial load, the second order effect ( $P-\Delta$ effect) should be involved in the analysis of the wallboard. The corresponding expression is as below.

$$
M_{\max }=M_{a}+P \Delta_{\max }
$$

where

$$
\Delta_{\max }=\frac{\mathbf{5} M_{\max } l^{2}}{\mathbf{4 8} E_{c} l_{e}}=\frac{M_{\max }}{K_{b}}
$$

$K_{b}$ can be equal to the flexural rigidity of the wallboard subjected to lateral load conservatively. The maximum moment $M_{a}$ at the middle height of the wallboard at the normal service condition will be coordinated with the deformation of wall $\Delta s$ by iterative method. The plane design of wallboard includes the overturning resistance checking calculation, shear resistance checking calculation, and the checking calculation shear fiction between wallboard and indoor floor.

\section{B. Cantilever Wallboard}

For the indoor firewall, in addition to adopting rigid frame, the cantilever wallboard with the bottom fixed can also be adopted if it plays no part in the distribution of shearing force. And then the mechanical model of wallboard can be simplified as the freely supported parapet with a length of $2 l_{c}$. For the semi-capped building, the wind load can be calculated as the half of the original value.

\section{Wallboard with the Bottom Fixed and the Top Hinged}

As is shown in Fig.8, for the convenience of the hoisting of wallboard, the wallboard can be designed with the bottom fixed and the top hinged. The wallboard can be simplified as the freely supported parapet with a calculating length of $0.7 l_{c}$.

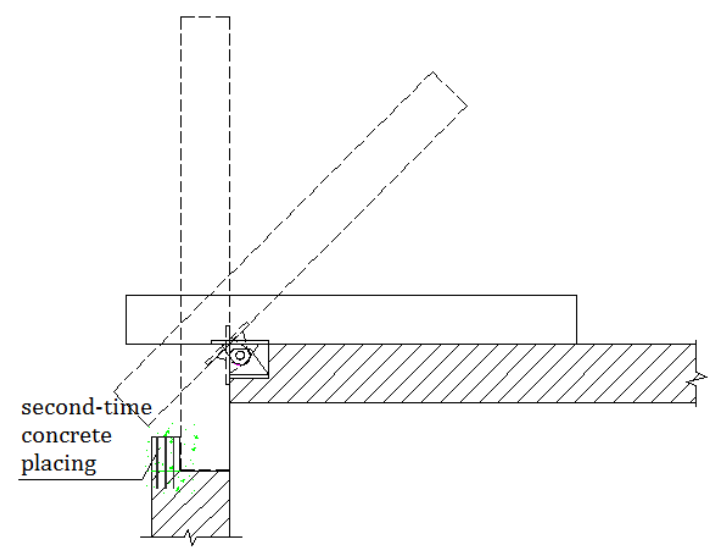

Fig. 8. Tilt-up wall with the bottom fixed and the top hinged.

\section{Analysis of Hoisting of Tilt-up Wallboard}

Generally, the wallboard can be hoisted after the concrete is conserved for seven to ten days. The whole process analysis should be conducted to guarantee the accuracy. To make the design easy, the wallboard can be simplified as the bending member along the span direction and the length direction. By analyzing the internal force when hoisting is started, the position of lifting point can be certified. For the load exerted on the wallboard, the gravity can only be considered. Considering the adhesive force, the safety factor can be 0.2 .

\section{DifFERENCE OF VELOCITY WIND PRESSURE AND THE CONVERSION}

The standard value of wind pressure is given as below in <Load code for the design of building structures> (GB50009-2012) [9].

$$
w_{k}=\beta_{z} \mu_{s} \mu_{z} w_{0}
$$

where $w_{0}$ is the basic wind pressure; $v_{0}$ is certified under five conditions including the geography being relatively flat and spacious, the height being $10 \mathrm{~m}$ above the ground, recurrence period being 50 years, the average time interval being $10 \mathrm{~min}$, and the wind speed being the maximum annual wind speed.

Subjected to wind load, the velocity wind pressure at the height of $z$ can be calculated as below [10].

$$
q_{z}=\mathbf{0 . 6 1 3} K_{z} K_{z t} K_{d} v_{\mathbf{0}}^{2}
$$

where $v_{0}$ is the basic wind speed certified under five conditions including the geography being relatively flat and spacious, the height being $10 \mathrm{~m}$ above the ground, recurrence period being 50 years, the average time interval being the time spent on the distance of 1 mile, and the wind speed being the maximum annual wind speed.

The relationship between different average wind speeds adopting the average time interval can be expressed as below.

$$
v_{t}(z)=v_{3600}(z)\left[\mathbf{1}+\sqrt{\beta} c_{t} / 2.5 \ln \left(z / z_{0}\right)\right]
$$

where $v_{t}(z)$ is the average wind speed with the average time interval being $t ; v_{3600}(z)$ is the average wind speed with the average time interval being $l h ; \beta$ is the parameter related to geography; $c_{t}$ can be confirmed according to the statistical analysis of the wind speed documents. The values of $c_{t}$ in standard geomorphology are shown in Table I.

TABLE I: THE VALUES OF THE PARAMETER

\begin{tabular}{ccccccc}
\hline \hline Time & 1 & 10 & 20 & 30 & 50 & 100 \\
\hline$c_{t}$ & 3 & 2.32 & 2 & 1.73 & 1.35 & 1.02 \\
Time & 200 & 300 & 600 & 1000 & 3600 & \\
$c_{t}$ & 0.7 & 0.54 & 0.36 & 0.16 & 0 & \\
\hline \hline
\end{tabular}

The conversion procedure is compiled adopting VB calculating language as below.

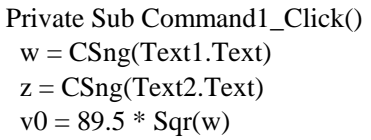




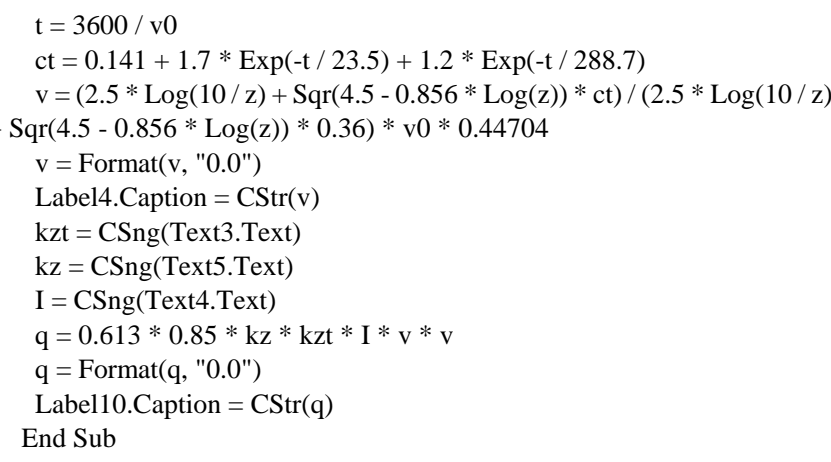

\section{DifFERENCE OF SEISMIC EFFECT AND THE CONVERSION}

\section{A. Conversion of Site Classification}

As shown is Table II [11], the conversion of site classification between two codes is conducted according to the equivalent velocity of shear wave.

TABLE II: CONVERSION OF SITE CLASSIFICATION

\begin{tabular}{cc}
\hline Code of Chinese \\
\hline
\end{tabular}

\section{B. Conversion of Ground Motion Parameters}

The relationship between two codes is as below.

$$
\left\{\begin{array}{l}
S_{S}=\mathbf{2 . 5} \gamma_{C N} A_{C C} / F_{a} \\
S_{\mathbf{1}}=\mathbf{2 . 5} \gamma_{C N} A_{C C} T_{g} / F_{v}
\end{array}\right.
$$

where $S_{S}, S_{1}$ are, respectively, the accelerated speed considering the short cycle at B-type site and the time of $1 \mathrm{~s}$ both under the maximum seismic effect stipulated in the ASCE; 2.5 is structural influence factor; $F_{a}$ and $F_{v}$ are the site parameters; $A_{c c}$ and $T_{g}$ are, respectively, the peak accelerated speed and the characteristic cycle of site-specific response spectrum both corresponding to the basic intensity stipulated in the code of Chinese; $\gamma_{C N}$ is the ratio of the peak accelerated speed with different recurrence periods.

The procedure is compiled adopting VB calculation language as below.

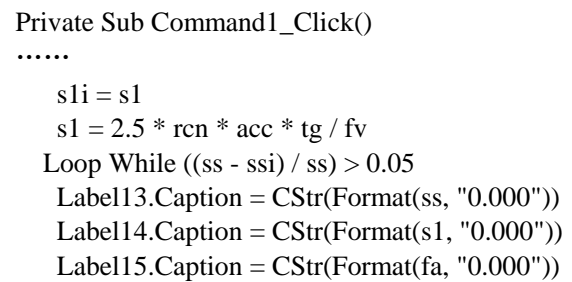

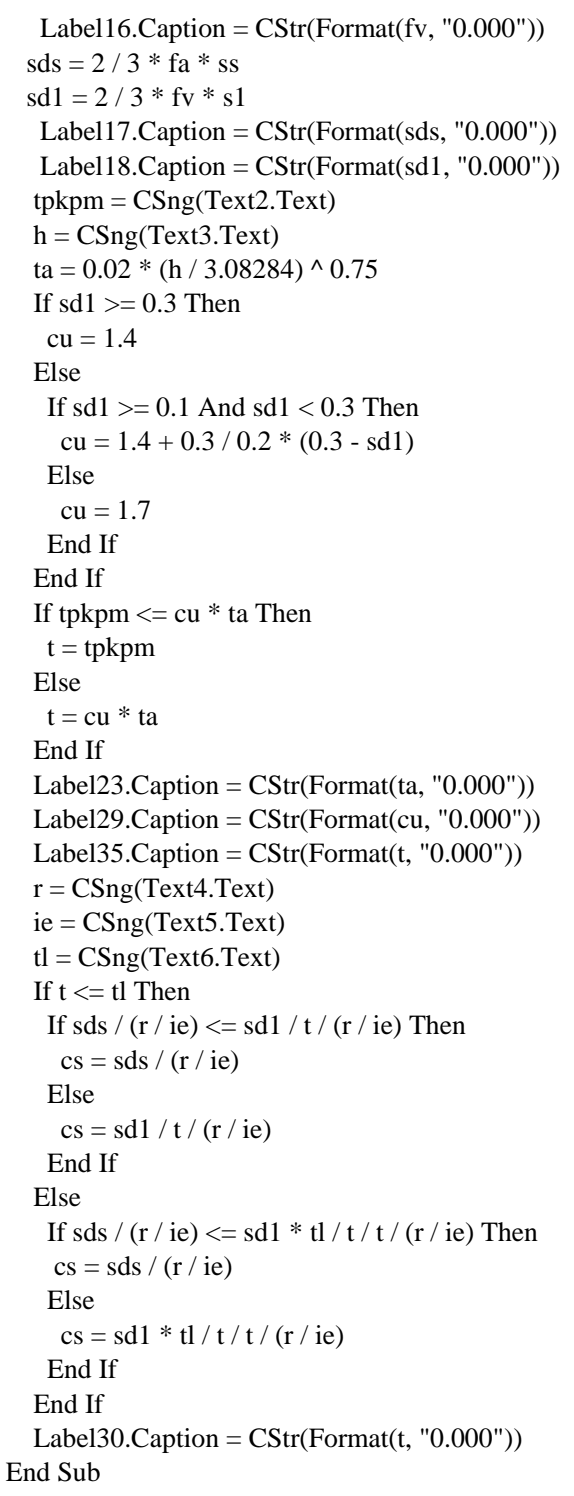

\section{CONCLUSION}

Comparing to portal frame, 'Tilt-up construction' is aesthetic, high-strength, collision resistant and needs to be repaired less frequently. Roof bracing and connection bracing are used replacing roof skin effect and deliver the shear force, which renders the design more suitable to the code.

Subjected to the lateral load along gable, the out-of-plane bending moment and deformation of the wallboard of the gable will be caused. The wallboard of the flank will be subjected to the in-plane shear force. The deformation along the span will exhibit the parabolic distribution. The maximum of deformation will appear at the middle span and gradually decrease along the length direction. The similar law can be found when the structure subjected to the lateral load along flank.

The Tilt-up wallboard with the bottom fixed and the top hinged and the corresponding design methods are proposed to make the hoisting of wallboard easier. The wallboard can be simplified as the bending member along the span and the length. The conversion between the code of Chinese and United States is conducted by compiling the procedure.

To realize the popularity of Tilt-up construction, it is 
suggested that the symmetrical calculating software is designed and applied to practical engineering. Simultaneously, mechanical problems of large scale wallboard during the process of hoisting and the mechanical behavior of joints are required to be studied.

\section{ACKNOWLEDGMENT}

We acknowledge the support from Shanghai Open Steel Structure Co., Ltd.

\section{REFERENCES}

[1] Q. Han, Y. H. Wang, G. W. Zhang, and H. Wu, "Introduction of tilt-up construction and details of connection," in Proc. 13th International Conference on Non-Conventional Materials and Technologies, pp. 952-957, vol. 517, Changsha, China, 2011.

[2] J. Nasvik, and B. Palmer, "Tilt-up concrete construction," Concrete Construction - World of Concrete, vol. 48, no. 9, pp. 48-50, September 2003.

[3] E. Sauter, "Tilt-up construction-not just for big boxes," Construction Specifier, vol. 57, no. 2, pp. 32-39, February 2004.

[4] J. Ruhnke, and C. J. Schexnayder, "Description of tilt-up concrete wall construction," Practice Periodical on Structural Design and Construction, vol. 7, no. 3, pp. 103-110, August 2002.

[5] Q. Han, Y. H. Wang, G.W. Zhang, and H. Wu, "Technology and application prospect of tilt-up construction in China," International Symposium on Ecological Environment and Technology of Concrete, pp. 418-424, vol. 477, Beijing, China, 2011.

[6] A. Engelman, "Tilt-up construction basics," Concrete Construction -World of Concrete, vol. 50, no. 10, pp. 28-32, October 2005.

[7] J. Collins, "Tilt-up dominates Australian construction," Concrete vol. 36, no. 3, pp. 36-37, March 2002.

[8] Design Guide for Tilt-Up Concrete Panels, ACI 551.2R-2010,

[9] Load Code for the Design of Building Structures, CECS GB50009-2012.

[10] Minimum Design Loads for Buildings and Other Structures, ANSI/ASCE7-2010.
[11] H. S. Lu, "Characterization of different site category method on strong ground motion," presented at the 14th World Conference on Earthquake Engineering, Beijing, China, October 12-17, 2008.

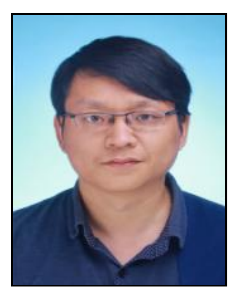

Jiankang Liu is with Shanghai Open Steel Structure Co., Ltd., Shanghai, 200127 China.

Mr. Liu was born in Jiangsu Province, China, in 1988. He is currently a structural engineer in Shanghai Open Steel Structure Co., Ltd.

Mr. Liu's current research interest includes research on prefabricated concrete structure, research on the tilt-up building system, key technology research in the process of hoisting.

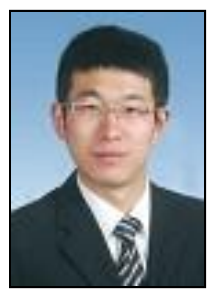

Jinling Gao was with Department of Civil Engineering, Shanghai University, Shanghai, 200444 China. He is now with Shanghai Open Steel Structure Co., Ltd. Shanghai, 200127 China.

Mr. Gao was born in Anhui Province, China, in 1993. $\mathrm{He}$ is currently an associate structural engineer with Jiankang Liu in Shanghai Open Steel Structure Co., Ltd.

Mr. Gao's current research interest includes mechanical response of new structures, interaction between structure and soil, mechanical theory and numerical methods research on bi-modulus materials and structures, structural mechanics in nuclear reactor technology, nanomechanics.

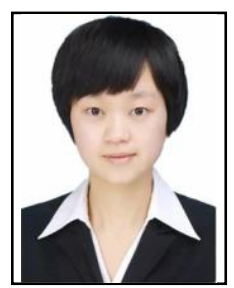

Tian Peng is with the Department of Civil Engineering, Tongji University, Shanghai, 200092, China.

Ms. Peng was born in Jiangxi Province, China, in 1992. She is a second-grade postgraduate in civil engineering in Tongji University, Shanghai, China.

Ms. Peng's current research interest includes Her currently research interests include structure fatigue research, aeolian vibration research of transmission lines, wind resistance of transmission lines and building structure. 